\title{
POTENCIAL ALELOPÁTICO DOS EXTRATOS DE FOLHAS E FRUTOS DE Pityrocarpa moniliformis SOBRE A GERMINAÇÃO DE SEMENTES DE Mimosa caesalpiniifolia
}

\author{
Mauro Vasconcelos Pacheco'; Francival Cardoso Felix²; Josenilda Aprígio Dantas de Medeiros ${ }^{3}$; Sarah Lima \\ Nunes4; Maria Luiza de Lima Castro5; Ana Luiza da Silva Lopes ${ }^{6}$; Wendy Mattos Andrade Teixeira de Souza ${ }^{7}$. \\ 1Unidade Acadêmica Especializada em Ciências Agrárias/Universidade Federal do Rio Grande do Norte \\ (UAECIA/UFRN), Macaíba, Rio Grande do Norte, Brasil, pachecomv@hotmail.com \\ ²UAECIA/UFRN, Macaíba, Rio Grande do Norte, Brasil, francival007@gmail.com \\ 3UAECIA/UFRN, Macaíba, Rio Grande do Norte, Brasil, josi-nilda@hotmail.com \\ ${ }^{4}$ UAECIA/UFRN, Macaíba, Rio Grande do Norte, Brasil, sarahnunes17@hotmail.com \\ ${ }^{5}$ UAECIA/UFRN, Macaíba, Rio Grande do Norte, Brasil, castro.luiza@hotmail.com \\ 6UAECIA/UFRN, Macaíba, Rio Grande do Norte, Brasil, analuizaslps@gmail.com \\ 7UAECIA/UFRN, Macaíba, Rio Grande do Norte, Brasil, wendymattos.a@gmail.com
}

RESUMO: A alelopatia tem sido definida como uma interação química entre espécies, por meio de metabólitos denominados aleloquímicos. O objetivo deste estudo foi avaliar o potencial alelopático dos extratos aquosos de folhas e frutos de Pityrocarpa moniliformis (Benth.) Luckow \& R. W. Jobson sobre a germinação de sementes e crescimento inicial de plântulas de Mimosa caesalpiniifolia Benth. Os extratos de folhas e de frutos de $P$. moniliformis foram obtidos por imersão em água destilada durante $24 \mathrm{~h}$, obtendo-se as concentrações de 0 (água destilada), 25, 50, 75 e $100 \mathrm{~g} \cdot \mathrm{L}^{-1}$. A semeadura foi realizada em papel toalha e as sementes mantidas para germinar a $25^{\circ} \mathrm{C}$ com fotoperíodo de $12 \mathrm{~h}$. As variáveis avaliadas foram: porcentagem de germinação, índice de velocidade de germinação, comprimento da raiz principal e da parte aérea de plântulas. A germinação de sementes de $M$. caesalpiniifolia não sofreu influência dos extratos de $P$. moniliformis, porém sua velocidade foi reduzida. $O$ extrato foliar reduziu o comprimento da raiz à medida que se aumentou a concentração até $57 \mathrm{~g} \cdot \mathrm{L}^{-1}$, enquanto os extratos dos frutos proporcionaram redução até a concentração de $68 \mathrm{~g} \cdot \mathrm{L}^{-1}$. O extrato de folhas acarretou no aumento do comprimento da parte aérea das plântulas, enquanto que o extrato dos frutos proporcionou redução até a concentração de $61,5 \mathrm{~g} \cdot \mathrm{L}^{-1}$. Os extratos aquosos de frutos e folhas de $P$. moniliformis não afetam a germinação de sementes de M. caesalpiniifolia, entretanto há efeito alelopático negativo sobre a velocidade e o crescimento inicial das plântulas de $M$. caesalpiniifolia.

PALAVRAS-CHAVE: Aleloquímicos, Heterotoxidade, Sementes florestais, Vigor. 


\title{
ALLELOPATHIC POTENTIAL OF LEAF AND FRUIT EXTRACTS OF Pityrocarpa moniliformis IN GERMINATION OF Mimosa caesalpiniifolia SEEDS
}

\begin{abstract}
An allelopathy has been defined as a chemical interaction between species, through metabolites called allelochemicals. The objective of this study was to evaluate the allelopathic potential of the aqueous extracts of leaves and fruits of Pityrocarpa moniliformis (Benth.) Luckow \& R. W. Jobson on seed germination and initial growth of Mimosa caesalpinilfolia Benth. seedlings. The leaves and fruit extracts of $P$. moniliformis were obtained by immersion in distilled water for $24 \mathrm{~h}$, obtaining as concentrations of 0 (distilled water), 25, 50, 75 and $100 \mathrm{~g} . \mathrm{L}^{-1}$. The seeding was performed on paper towel and as seeds kept to germinate at $25^{\circ} \mathrm{C}$ with photoperiod of $12 \mathrm{~h}$. The variables evaluated were: percentage of germination, germination speed index, length of root and aerial part seedlings. Germination of $M$. caesalpinilfolia seeds was not influenced by the extracts of $P$. moniliformis, but its velocity was reduced. The leaf extract reduced root length as the concentration increased to $57.0 \mathrm{~g} \mathrm{LL}^{-1}$, while fruit extracts reduced the concentration to 68.0 g. $\mathrm{L}^{-1}$. The extract of leaves led to an increase on length of aerial part seedlings, whereas the extract of the fruits proposed the reduction up to concentration of $61.5 \mathrm{~g} . \mathrm{L}^{-1}$. The aqueous extracts of fruits and leaves of $P$. moniliformis do not affect the germination of $M$. caesalpinilfolia seeds, however, there is negative allelopathic effect on speed and initial growth of M. caesalpiniifolia seedlings.
\end{abstract}

KEYWORDS: Allelochemicals, Forest seeds, Heterotoxicity, Vigor.

\section{POTENCIAL ALELOPÁTICO DE LOS EXTRACTOS DE HOJAS Y FRUTOS DE Pityrocarpa moniliformis SOBRE LA GERMINACIÓN DE SEMILLAS DE Mimosa caesalpinïfolia}

RESUMEN: La alelopatía se ha definido como una interacción química entre especies, por medio de metabólitos nombrados aleloquímicos. El objetivo de este estudio fue evaluar el potencial alelopático de los extractos acuosos de hojas y frutos de Pityrocarpa moniliformis (Benth.) Luckow \& R. W. Jobson sobre la germinación de semillas y el crecimiento inicial de plántulas de Mimosa caesalpiniifolia Benth. Los extractos de hojas y de frutos de $P$. moniliformis fueron obtenidos por inmersión en agua destilada durante 24 horas, obteniendo las concentraciones de 0 (agua destilada), 25, 50, 75 y 100 g.L $\mathrm{L}^{-1}$. La siembra fue realizada en papel toalla y las semillas mantenidas para germinar a $25^{\circ} \mathrm{C}$ con fotoperíodo de 12 horas. Las variables evaluadas fueron: porcentaje de germinación, índice de velocidad de germinación, longitud de la raíz principal y de la parte aérea de plántulas. La germinación de semillas de $M$. caesalpiniifolia no sufrió influencia de los extractos de P. moniliformis, pero su velocidad fue reducida. El extracto foliar redujo la longitud de la raíz a medida que se aumentó la concentración hasta $57 \mathrm{~g} \cdot \mathrm{L}^{-1}$, mientras que los extractos de los frutos proporcionaron una reducción hasta la concentración de $68 \mathrm{~g} \cdot \mathrm{L}^{-1}$. El extracto de hojas 
acarreó en el aumento de la longitud de la parte aérea de las plántulas, mientras que el extracto de los frutos proporcionó reducción hasta la concentración de $61,5 \mathrm{~g} \cdot \mathrm{L}^{-1}$. Los extractos acuosos de frutos y hojas de P. moniliformis no afectan la germinación de semillas de M. caesalpiniifolia, sin embargo hay efecto alelopático negativo sobre la velocidad y el crecimiento inicial de las plántulas de M. caesalpiniifolia.

PALABRAS CLAVE: Aleloquímicos, Heterotoxicidad, Semillas forestales, Vigor.

\section{INTRODUÇÃO}

A Caatinga ocupa uma área de aproximadamente $800.000 \mathrm{~km}^{2}$ (70\% de toda a região Nordeste), com ocorrência nos Estados do Piauí, Ceará, Rio Grande do Norte, Paraíba, Pernambuco, Alagoas, Sergipe, Bahia e uma pequena faixa no norte de Minas Gerais (PRADO, 2003; LEITE; MACHADO, 2009). A vegetação desse bioma é predominantemente arbustivo-arbórea, com plantas de porte baixo, em torno de 4 a $7 \mathrm{~m}$ de altura, tendo como características: ramificações intensas, lignificação precoces, emaranhado de galhos, ramos com espinhos ou acúleos, e por vezes tricomas urticantes (QUEIROZ, 2009).

Dentre as espécies nativas que compõem esse bioma, encontra-se a Mimosa caesalpiniifolia Benth. (Fabaceae), essa espécie foi introduzida em regiões úmidas no Estado do Rio de Janeiro e de São Paulo, onde tem se adaptado com êxito (HOLANDA et al., 2015). Sendo bastante empregada em cerca viva e ideal para reflorestamentos em áreas degradada por sua tolerância à luz direta e rápido crescimento (LORENZI, 1998).

Além disso, as raízes de $M$. caesalpiniifolia auxiliam na assimilação de nitrogênio do solo (MARTINS et al., 2015) e os galhos possuem usos madeireiros devido às suas propriedades de resistência e durabilidade, entretanto, a espécie tem sido explorada de modo indiscriminado ao longo dos anos (FREITAS et al., 2011; NOGUEIRA et al., 2013).

Pityrocarpa moniliformis (Benth.) Luckow \& R. W. Jobson (Fabaceae) é uma espécie endêmica do Brasil que ocorre ao longo da região Nordeste e no Estado de Minas Gerais (MAIA-SILVA et al., 2012), podendo ser utilizada em reflorestamentos, atuando no combate à erosão e na primeira e segunda fase da recomposição florestal de áreas degradadas (MAIA, 2004). Além de ser 
usualmente empregada na alimentação de rebanhos de caprinos e bovinos em comunidades rurais do Rio Grande do Norte (LOIOLA et al., 2010).

A alelopatia tem sido definida pela Sociedade Internacional de Alelopatia como a influência de metabólitos secundários produzidos por plantas, algas, bactérias e fungos, que afetam o desenvolvimento e crescimento de outros organismos (REIGOSA et al., 2013). Essa influência deve-se aos aleloquímicos produzidos e lançados no meio, os quais possuem diversas rotas para o ambiente, como por via aérea, no caso dos terpenos que são voláteis; e por lixiviação e decomposição de partes das plantas que irão compor a serapilheira (FERREIRA; BORGHETTI, 2004).

As plantas armazenam os aleloquímicos em folhas, flores, frutos, raízes, rizomas, caules e sementes, porém a concentração em cada estrutura difere e os meios de liberação são diferentes para cada espécie (PUTNAN; TANG, 1986). A alelopatia mantém duas formas de ação: direta (agindo sobre as membranas celulares e/ou mesmo nos processos celulares) e indireta (alterando as atividades dos microrganismos) (BLUM, 2011).

Dado o esboço, o objetivo deste estudo foi avaliar o potencial alelopático dos extratos aquosos de folhas e frutos de P. moniliformis sobre a germinação de sementes e crescimento inicial de plântulas de M. caesalpiniifolia.

\section{MATERIAL E MÉTODOS}

O experimento foi conduzido no Laboratório de Sementes Florestais da Unidade Acadêmica Especializada em Ciências Agrárias, da Universidade Federal do Rio Grande do Norte (UAECIA/UFRN), localizada na Escola Agrícola de Jundiaí (EAJ) em Macaíba/RN, Brasil.

As folhas verdes e os frutos maduros sem sementes de $P$. moniliformis foram coletados na Área de Experimentação Florestal da EAJ e imediatamente submetidos à secagem em estufa a $60{ }^{\circ} \mathrm{C}$ durante 24 h. Em seguida, estes foram imersos em água destilada à temperatura de $25 \pm 4{ }^{\circ} \mathrm{C}$, durante 24 h para obter as concentrações 25, 50, 75 e $100 \mathrm{~g} . \mathrm{L}^{-1}$, além do tratamento controle $\left(0 \mathrm{~g} \cdot \mathrm{L}^{-1}\right)$ obtido somente com 
água destilada. $\mathrm{O} \mathrm{pH}$ das soluções foi mensurado com pHmetro digital.

Os frutos de M. caesalpiniifolia foram coletados na Área de Experimentação Florestal da EAJ em dezembro de 2016, e as sementes foram beneficiadas e armazenadas em refrigerador $\left(5 \pm 4{ }^{\circ} \mathrm{C} ; 30 \%\right.$ de U.R.). Inicialmente, duas subamostras de 4,5 g de sementes foram postas para secar em estufa a $105 \pm 3{ }^{\circ} \mathrm{C}$ durante $24 \mathrm{~h}$ para a obtenção do teor de água (BRASIL, 2009).

Para os testes de germinação, quatro repetições de 25 sementes para cada tratamento foram escarificadas por meio de desponte na região oposta ao hilo (BRUNO et al., 2001) e desinfestadas com solução de hipoclorito de sódio a 2,5\% durante três minutos, posteriormente, as mesmas foram semeadas em três folhas de papel toalha (tipo Germitest $^{\circledR}$ ), organizadas em sistema de rolos e acondicionadas em germinador do tipo B.O.D. (Biochemical Oxygen Demand) à temperatura de $25^{\circ} \mathrm{C}$ com fotoperíodo de 12 h (BRASIL, 2013).

Foram feitas as seguintes avaliações: a) germinação - foi contabilizado o número de plântulas normais (BRASIL, 2009) ao sexto dia após a semeadura, com os resultados expressos em porcentagem (\%); b) índice de velocidade germinação (IVG) - em conjunto com o teste de germinação, contabilizando-se o número de plântulas normais, e calculado conforme Maguire (1962); c) comprimento de plântulas - com o auxílio de um paquímetro digital $(0,01 \mathrm{~cm})$ foram mensurados os comprimentos da raiz principal e da parte aérea das plântulas normais resultantes do teste de germinação, cujos resultados foram expressos em centímetros (cm).

O delineamento experimental foi inteiramente casualizado em arranjo fatorial $2 \times 5$ (dois tipos de extratos e cinco concentrações). Os dados foram submetidos à análise de variância (ANOVA) com o auxílio do programa estatístico ASSISTAT (SILVA, 2015), sendo adotadas as equações polinomiais com maior significância e coeficiente de determinação $\left(R^{2}\right)$.

\section{RESULTADOS E DISCUSSÃO}

A conservação da qualidade fisiológica das sementes se deve à adequada manutenção do grau de umidade 
(OLIVEIRA et al., 2015), o qual deve estar abaixo de $10 \%$ para que os testes possam ser conduzidos de forma confiável e reproduzíveis (MARCOS FILHO, 1999). No presente estudo, o teor de água obtido para as sementes de M. caesalpiniifolia foi de 9,3\%, ou seja, abaixo dos limites de tolerância.

A influência do potencial hidrogeniônico (pH) e da concentração de extratos brutos são parâmetros que interferem diretamente na germinação, uma vez que os extratos podem ter substâncias como açúcares, aminoácidos e ácidos orgânicos, os quais podem disfarçar a interferência dos aleloquímicos por interferir na concentração iônica ou no potencial osmótico (REIGOSA; PEDROL, 2002; MAIA et al., 2013).

Além disso, o $\mathrm{pH}$ pode interferir no crescimento das plântulas, quando o mesmo for extremamente alcalino ou ácido, com efeitos nocivos observados em substâncias com pH abaixo de 4 (ácido) e superior a 10 (alcalino) (EBERLEIN, 1987; MAIA et al., 2013). Os extratos de P. moniliformis avaliados são moderadamente ácidos, em que os extratos aquosos dos frutos apresentamse entre 4,5- 4,8 e das folhas, 5,0-5,4 (Tabela 1), ambos dentro da faixa de tolerância para que o processo germinativo ocorra sem prejuízos.

Tabela 1. Valores referente ao pH das concentrações de extratos aquosos de frutos e folhas de P. moniliformis.

\begin{tabular}{|c|c|c|}
\hline Concentrações/ Extrato g.. L $^{-1}$ & Frutos & Folhas \\
\hline 25 & 4,8 & 5,2 \\
\hline 50 & 4,7 & 5,0 \\
\hline 75 & 4,5 & 5,0 \\
\hline 100 & 4,5 & 5,4 \\
\hline
\end{tabular}

Verificou-se que as sementes de $M$. caesalpinïfolia não sofreram alteração significativa no seu percentual de germinação com os tratamentos aplicados e que as concentrações dos extratos não interferiram diretamente neste processo (Figura 1A). O teste de germinação geralmente não apresenta a 
influência dos aleloquímicos sobre as processo germinativo (FERREIRA; sementes, teste considerado pouco BORGHETTI, 2004).

sensível, visto que os efeitos são tardios no

Figura 1. Germinação (A) e índice de velocidade de germinação - IVG (B) de sementes de M. caesalpinïfolia sob efeito dos extratos aquosos de folhas e frutos de P. moniliformis.

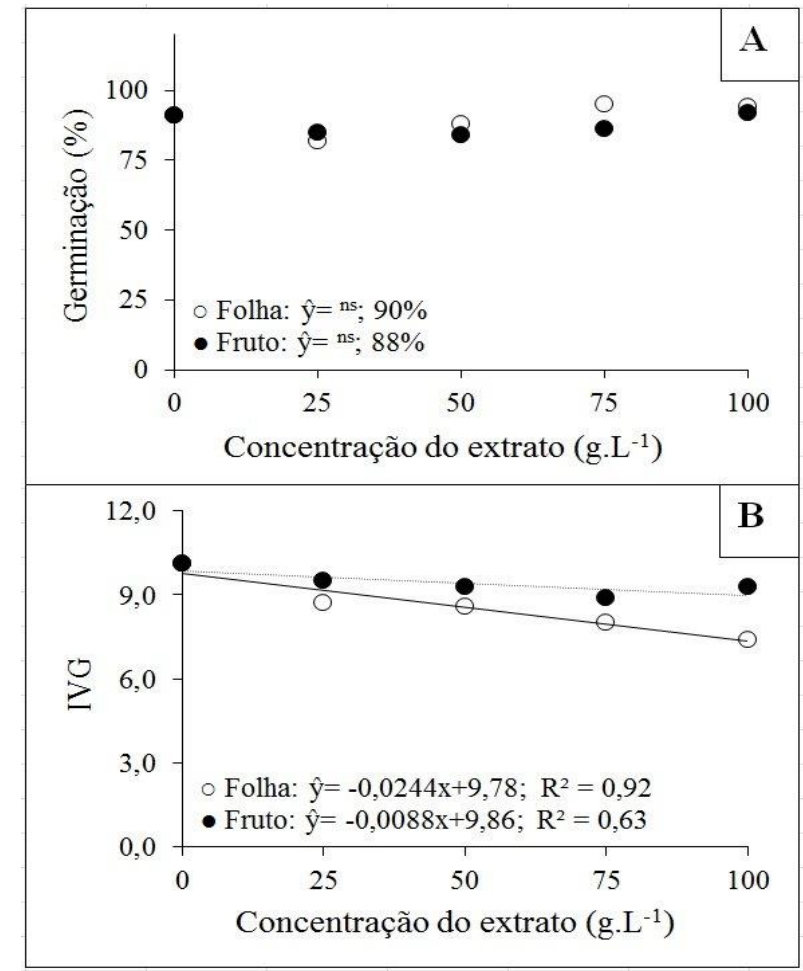

Apesar de não ter havido influência dos extratos sobre a porcentagem de germinação, é possível observar que a velocidade do processo germinativo sofreu redução acentuada à medida que se aumentou a concentração dos extratos foliares, enquanto que os extratos dos frutos apresentaram redução pouco significativa (Figura 1B). Não há estudos anteriores acerca do potencial alelopático de P. moniliformis, entretanto há pesquisas com outras espécies também pertencentes à família Fabaceae, a exemplo de Lessa et al. (2017), os quais observaram que os extratos foliáceos produzidos com folhas de Amburana cearensis interferiram negativamente no índice de velocidade de germinação das sementes Amaranthus deflexus, 
similarmente ao observado no presente estudo.

Os extratos aquosos de folhas e frutos de P. moniliformis interferiram negativamente no crescimento inicial das plântulas de M. caesalpiniifolia (Figuras 2 $A$ e $B$ e 3).

O extrato foliar afetou o crescimento das raízes de modo inversamente proporcional até a concentração de 57,0 g. L $^{-1}$, enquanto os extratos dos frutos proporcionaram redução até a concentração de 68,0 g.L.-1 (Figura 2A).

Em pesquisa realizada avaliando o efeito do extrato de ramos jovens de Croton sonderianus sobre a germinação de sementes de Lactuca sativa, observouse diferença significativa para as variáveis germinação, crescimento de plântula e comprimento da raiz primária (PARENTE et al., 2014).

Figura 2. Comprimento da raiz (A) e parte aérea (B) de plântulas oriundas de sementes de M. caesalpiniifolia sob efeito dos extratos aquosos de folhas e frutos de $P$. moniliformis.

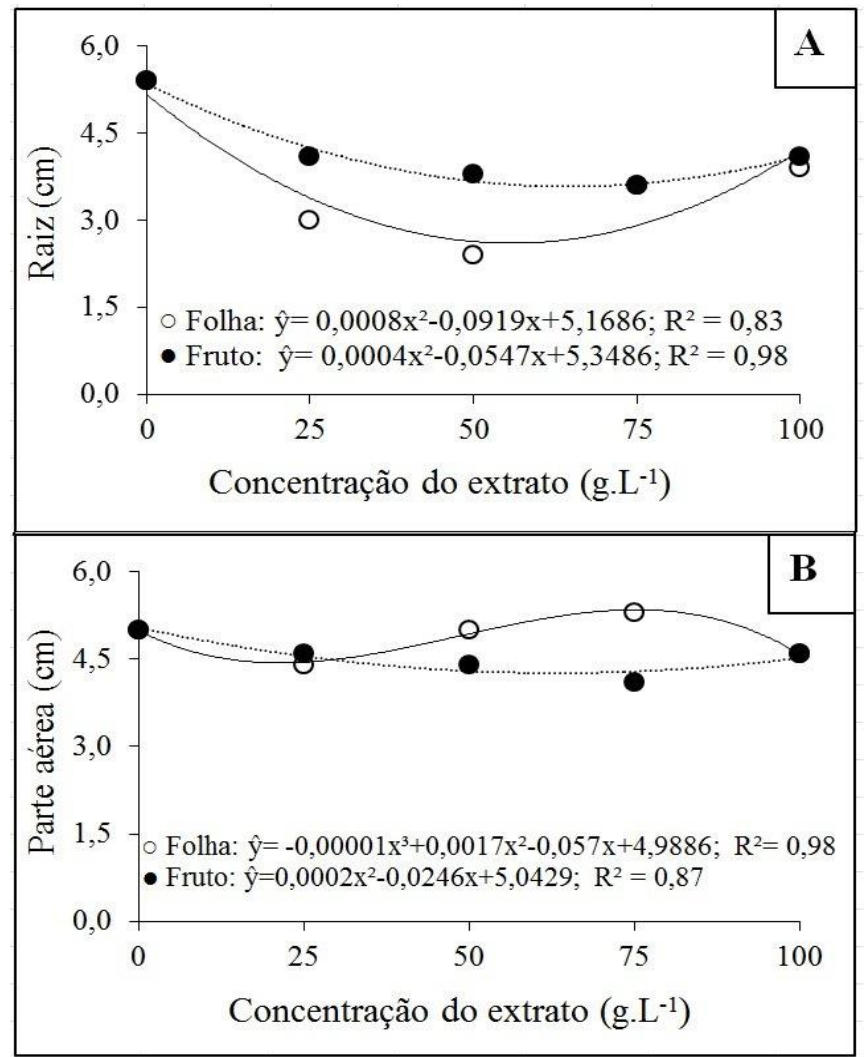


O extrato a partir de frutos ocasionou efeito negativo no comprimento da parte aérea até a concentração de 61,5 g.L-1, enquanto os extratos foliares proporcionaram incremento no comprimento da parte aérea (Figura 2B). As raízes geralmente apresentam maior sensibilidade que a parte aérea na detecção de efeito alelopático, o que pode ser explicado devido ao contato direto com o extrato (CHUNG et al., 2001; BORELLA et al., 2009). As folhas e frutos de P. moniliformis apresentam em sua composição saponinas, flavonóides, triterpenos e taninos gálicos
(SILVA, et al., 2013; ALVES et al., 2014), aleloquímicos possivelmente atuantes neste estudo.

A morfologia das plântulas de $M$. caesalpinïfolia apresenta-se pouco diferenciada, tanto entre as concentrações, quanto entre os tipos de extratos (Figura 3). Observou-se que as plântulas expostas ao extrato dos frutos apresentaram raízes mais desenvolvidas, porém na concentração de 100 g.L $\mathrm{L}^{-1}$, independentemente do tipo de extrato, houve desenvolvimento mais lento dos eófilos (primeiras folhas).

Figura 3. Plântulas de M. caesalpiniifolia originadas de sementes submetidas aos extratos aquosos de folhas e frutos de P. moniliformis. (eo: eófilo, ct: cotilédone, hp: hipocótilo e rz: raiz primária).
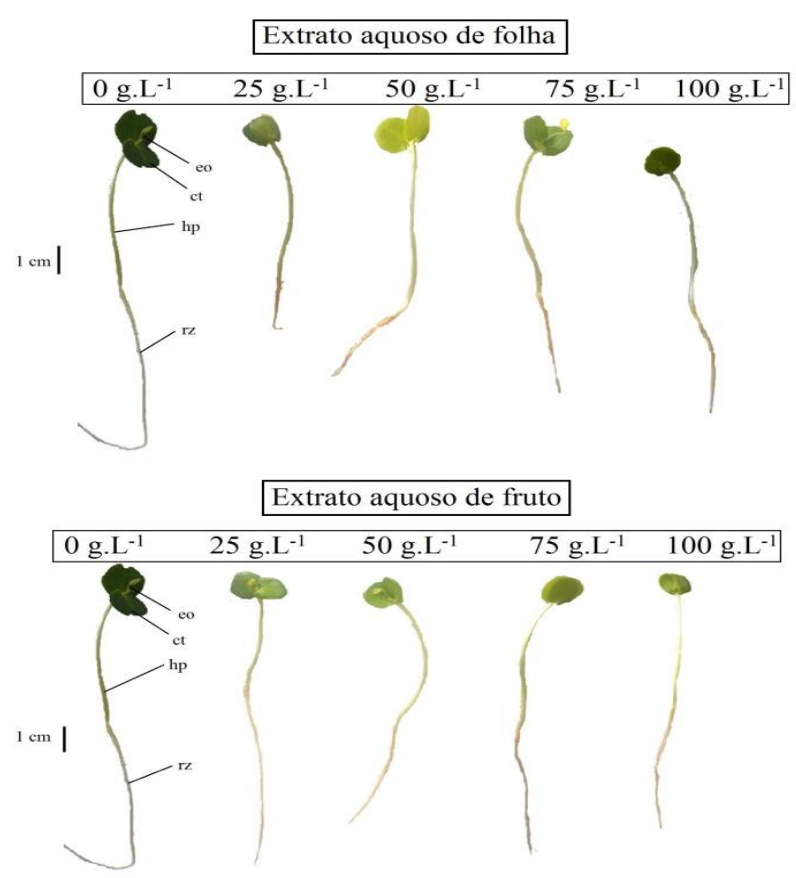
As sementes de M. caesalpiniifolia possivelmente apresentam mecanismos bioquímicos e fisiológicos de auto ajuste contra os efeitos dos extratos aquosos que possam causar danos durante a germinação, possivelmente uma estratégia ecológica da espécie. Apesar da interferência negativa no crescimento das raízes, o presente estudo verificou pouca ocorrência de plântulas anormais, parâmetro importante de expressão alelopática. Em estudo que avaliou o crescimento inicial de plântulas de $L$. sativa foram observadas anormalidades na parte aérea e sistema radicular, como estruturas atrofiadas, defeituosas, ausentes e oxidadas (CARVALHO, et al., 2014).

\section{CONCLUSÕES}

Os extratos aquosos de frutos e de folhas de $P$. moniliformis não afetam a germinação de sementes de $M$. caesalpiniifolia, entretanto há efeito alelopático negativo sobre a velocidade e o crescimento inicial de plântulas de $M$. caesalpinïfolia.

\section{AGRADECIMENTOS}

À Fundação de Apoio à Pesquisa do Rio Grande do Norte (FAPERN), pelo apoio financeiro.

À Coordenação de Aperfeiçoamento de Pessoal de Nível Superior (CAPES) pela concessão de bolsas para o segundo, terceiro e quarto autores.

Ao Conselho Nacional de Desenvolvimento Científico e Tecnológico (CNPq), pela concessão de bolsa de iniciação científica ao quinto e ao sexto autores.

\section{REFERÊNCIAS}

ALVES, M.J.; MOURA, A.K.S.; COSTA, L.M.; ARAÚJO, E.J.F.; SOUSA, G.M.; COSTA, N.D.J.; FERREIRA, P.M.P.; SILVA, J.N.; PESSOA, C.; LIMA, S.G.; CITÓ, A.M.G.L. Teor de fenóis e flavonoides, atividades antioxidante e citotóxica das folhas, frutos, cascas dos frutos e sementes de Piptadenia moniliformis Benth (Leguminosae - Mimosoideae). Boletín Latinoamericano y del Caribe de Plantas Medicinales y Aromáticas, v.13, n.5, p.466476, 2014.

BLUM, U. Plant-Plant allelopathic interactions: Phenolic Acids, Crop Cover and Weed Emergence. Springer. 2011.

BORELLA， J; WANDSCHEER， A. C. D; BONATTI, L. C; PASTORINI, L. H. Efeito alelopatico de extratos aquosos de Persea americana Mill. Sobre Lactuca sativa L. 
Revista Brasileira de Biociencias, v. 7, n.3, p. 260-265, 2009.

BRASIL. Ministério da Agricultura, Pecuária e Abastecimento. Regras para análise de sementes. Ministério da Agricultura, Pecuária e Abastecimento. Secretaria de Defesa Agropecuária. Brasília: MAPA/ACS, 2009. 399 p.

BRASIL. Ministério da Agricultura, Pecuária e Abastecimento. Instruções para a análise de sementes de espécies florestais. Ministério da Agricultura, Pecuária e Abastecimento. Secretaria de Defesa Agropecuária. Brasília: MAPA/ACS, 2013. $98 \mathrm{p.}$

BRUNO, R.L.A.; ALVES, E.U.; OLIVEIRA, A.P.; PAULA, R.C. Tratamentos prégerminativos para superar a dormência de sementes de Mimosa caesalpiniaefolia Benth. Revista Brasileira de Sementes, v. 23, n. 2, p. 136-143, 2001.

CARVALHO, W. P; CARVALHO, G. J.; ABBADE NETO, D. O; TEIXEIRA, L. G. V. Alelopatia de extratos de adubos verdes sobre a germinação e crescimento inicial de alface. Bioscience Journal, v. 30, n. 1, p. 1-11, 2014.

CHUNG, I. M.; AHN, J. K; YUN, S. J. Assessment of allelopathic potential of barnyard grass (Echinochloa crus-gall) on rice (Oriza sativa L.) cultivars. Crop Protection, v.20, p. 921-928, 2001.

EBERLEIN, C. V. Germination of Sorghum almum seeds and longevity in soil. Weed Science. v. 35, n. 6, p. 796-801, 1987.

FERREIRA, A. G; BORGHETTI, F. Germinação: do básico ao aplicado. Porto Alegre: Artmed, 2004. 323 p.
FREITAS, R. M. O.; SOUZA PINTO, J. R.; PRAXEDES, S. C.; NOGUEIRA, N. W.; RIBEIRO, M. C. C. Gibberellic acid stimulus on seed and seedling performance is dependent on pod position in Mimosa caesalpinïfolia. Seed Science \& Technology, v. 39, n. 3, p. 660-665, 2011.

HOLANDA, A. E. R; MEDEIROS FILHO, S; DIOGO, I. J. S. Influência da luz e da temperatura na germinação de sementes de sabiá (Mimosa caesalpinüfolia Benth.Fabaceae). Gaia Scientia, v. 9, p. 22-27, 2015.

LEITE, A.V; MACHADO, I. C. Biologia reprodutiva da "catingueira" (Caesalpinia pyramidalis Tul., LeguminosaeCaesalpinioideae), uma espécie endêmica da Caatinga. Revista Brasilica Botânica, v. 32, n. 1, p.79-88, 2009.

LESSA, B. F. T. SILVA, M. L. S; BARRETO, J. H. B.; OLIVEIRA, A. B. Efeitos alelopáticos de extratos aquosos de folhas de Amburana cearensis e Plectranthus barbatus na germinação de Amaranthus deflexus. Revista de Ciências Agrárias, v. 40, n. 1, p.79-86, 2017.

LOIOLA, M. I. B.; PATERNO, G. B. C.; DINIZ, J. A.; CALADO, J. F.; OLIVEIRA, A. C. $P$. Leguminosas e seu potencial de uso em comunidades rurais de São Miguel do Gostoso - RN. Mossoró: Revista Caatinga, v. 23-3. p. 59-70, 2010.

LORENZI, H. Árvores brasileiras: manual de identificação e cultivo de plantas arbóreas nativas do Brasil. Nova Odessa: Ed. Plantarum. 1998. 351 p.

MAGUIRE, J.D. Speed of germination aid selection and evaluation for seedling 
emergence and vigour. Crop Science, Madison, v.2, n.2, p.176-177, 1962.

MAIA, G. N. Caatinga: árvores e arbustos e suas utilidades. São Paulo: D \& Z Computação Gráfica e Editora, 2004. 413 p.

MAIA, S. S. S.; COELHO, M. F. B.; OLIVEIRA, A. K. DIÓGENES, F. E. P. Atividade biológica de extratos de espécies do Rio Grande do Norte em sementes de alface. Revista Verde de Agroecologia e Desenvolvimento Sustentável, v. 8, n. 4, p.169-173, 2013.

MAIA-SILVA, C.; SILVA, C.I; HRNCIR, M.; QUEIROZ, R.T.; IMPERATRIZ-FONSECA, V.L. Guia de Plantas - visitadas por abelhas na Caatinga, Fundação Brasil Cidadão. 2012. 99 p.

MARCOS FILHO, J. Teste de envelhecimento acelerado. In: KRZYZANOWSKI, F.C.; VIEIRA, R.D.; FRANÇA-NETO, J.B. (Ed.). Vigor de sementes: conceitos e testes. Londrina: ABRATES, 1999. cap.3, p.1-24.

MARTINS, P. G. S.; JUNIOR, M. A. L.; FRACETTO, G. G. M.; SILVA, M. L. R. B.; VINCENTIN, R. P.; LYRA, M. C. C. P. Mimosa caesalpinilfolia rhizobial isolates from different origins of the Brazilian Northeast. Archives of Microbiology, v. 197, p. 1-10, 2015.

NOGUEIRA, N. W; RIBEIRO, M. C. C; FREITAS, R. M. O; GURGEL, G. B; NASCIMENTO, I. L. Diferentes temperaturas e substratos para germinação de sementes de Mimosa caesalpiniiffolia Benth. Revista Ciências Agrarias, v. 56, n. 2, p. 95-98, 2013.
OLIVEIRA, L.M.; BRUNO, R.L.A.; MENEGHELLO, G.E. Qualidade fisiológica de sementes de Syzygium cumini L. durante 0 armazenamento. Ciência Florestal, v. 25, n. 4, p. 921-931, 2015.

PARENTE, K. M. S.; SILVA, L. S.; MOURÃO, E. B.. Efeito alelopático de extratos de ramos jovens de Croton sonderianus Muell. Arg., Euphorbiaceae, na germinação de Lactuca sativa L. Ciências Agrárias/fitotecnia, v. 16, n. 1, p. 27-42, 2014.

PRADO, D. E. As Caatingas da América do Sul. In Ecologia e conservação da Caatinga (I.R. LEAL, M. TABARELLI; J.M.C. SILVA, eds.). Editora Universitária, UFPE, Recife, 2003. p. 3-73.

PUTNAN A. R; TANG C. S. In: PUTNAN A. $R ;$ TANG C. S. The science of allelopathy. New York: John Wiley \& Sons. p. 1-19. 1986.

REIGOSA, M.; PEDROL, N. Allelopathy from molecules to ecosystems. Plymouth: Science Publishers, 2002. 316 p.

REIGOSA, M; GOMES, A. S; FERREIRA, A.G; BORGHETTI, F. Allelopathic research in Brazil. Acta Botanica Brasilica, v. 27, n. 4, p. 629-646, 2013.

QUEIROZ, L. P. Leguminosas da Caatinga. Feira de Santana: UEFS, 2009. 467 p.

SILVA, J. F. V.; SILVA, L. C. N.; ARRUDA, I. R. S.; SILVA, M. V. Antimicrobial activity of Pityrocarpa monilifomis leavesand its capacity to enhance the activity of four antibiotics against Staphylococcus aureus strains. Journal of Medicinal Plants Research, v. 7, n. 28, p. 2067-2072, 2013. 
SILVA, F.A.S. ASSISTAT; versão 7.7 beta.

DEAG-CTRN-UFCG. 2015. Disponível em:

$<$ http://www.assistat.com/indexp.html>.

Acesso em: 10 nov. 2016. 